\title{
QUALIDADE DA ÁGUA DO RIBEIRÃO LAVRINHA NA REGIÃO ALTO RIO GRANDE - MG, BRASIL ${ }^{1}$
}

\author{
Water quality on Lavrinha Stream in Alto Rio Grande region, \\ Minas Gerais State, Brazil
}

\author{
Daniel Brasil Ferreira Pinto ${ }^{2}$, Antônio Marciano da Silva ${ }^{3}$, Carlos Rogério de Mello $^{4}$, Gilberto Coelho $^{5}$
}

\begin{abstract}
RESUMO
Conduziu-se este trabalho, com principal objetivo de estudar o comportamento da qualidade da água, ao longo do tempo, em uma bacia hidrográfica de cabeceira do Rio Grande, MG. A bacia hidrográfica apresenta uma área de 687 ha e está situada na Serra da Mantiqueira. Foram amostrados seis pontos no Ribeirão Lavrinha no período de maio de 2006 a janeiro de 2007, totalizando sete amostragens. O mapa de uso atual do solo foi gerado a partir de levantamento em campo com auxilio de GPS. Os parâmetros analisados foram: potencial hidrogeniônico $(\mathrm{pH})$, oxigênio dissolvido $(\mathrm{OD})$, condutividade elétrica, salinidade, temperatura, demanda bioquímica de oxigênio (DBO), demanda química de oxigênio (DQO), nitrato $\left(\mathrm{NO}_{3}^{-}\right)$, nitrogênio amoniacal $\left(\mathrm{NH}_{3}\right)$, fósforo $\left(\mathrm{PO}_{4}\right)$, turbidez, sólidos totais, sólidos totais dissolvidos (TDS), coliformes termotolerantes (Escherichia coli), coliformes totais. Para os dados calculou-se o Índice de Qualidade da Água (IQA), proposto pelo Instituto Mineiro de Gestão das Águas (IGAM) e fez-se o enquadramento em classes conforme Resolução 357/05 CONAMA. As condições ambientais refletiram-se tanto nos valores do IQA quanto no processo de enquadramento. Constatou-se ainda que o principal fator causador do quadro crítico é o NMP de coliformes, o qual se associa com a pecuária. Em menor escala o OD e a DBO são também fatores limitantes.
\end{abstract}

Termos para indexação: Recursos Hídricos, IQA, qualidade da água, bacia hidrográfica do Ribeirão Lavrinha, MG.

\section{ABSTRACT}

The main purpose of this work was to study the surface water quality behavior, continuously throughout the time, at the headwater watershed of the Grande River, MG. The watershed drains into Grande River area of 687 ha and is enclosed by the Mantiqueira Mountains. The samples were collected at six points in Lavrinha Stream, main tributary of the watershed, from May 2006 to January 2007, with a total of seven evaluations for each point. Current watershed land use map was developed through GPS device, based on field observations. The parameters evaluated were: hydrogen potential ( $\mathrm{pH}$ ), Dissolved Oxygen (DO), electric conductivity (EC), salinity, temperature, Biochemical Oxygen Demand (BOD), Chemical Oxygen Demand (COD), nitrate $\left(\mathrm{NO}_{3}^{-}\right)$, ammonia $\left(\mathrm{NH}_{3}\right)$, phosphorous $\left(\mathrm{PO}_{4}\right)$, turbidly, total soil, total dissolved soil (TDS), fecal coliform (Escherichia coli), total coliform. Water Quality Index (WQI), proposed by "Minas Gerais State Water Resources Institute" (IGAM), was calculated for all samples, classifying the water quality class according to CONAMA Resolution 357/ 05. The environmental conditions reflected on WQI values as well as on CONAMA water quality classification. It was evidenced that the main parameter of the critical situation of the water quality at watershed was the fecal and total coliform, which is associated to livestock. Although less important than coliform, DO and BOD are also limiting parameters at watershed.

Index terms: Water resources, WQI, water quality, Lavrinha Stream Watershed.

\section{(Recebido em 30 de março de 2007 e aprovado em 15 de maio de 2008)}

\section{INTRODUÇÃO}

A demanda por água de boa qualidade tem aumentado consideravelmente nas últimas décadas em razão do crescimento desordenado da população. As atividades humanas ocorrem em bacias hidrográficas, sejam elas rurais ou urbanas, alterando suas características e contribuindo para a mudança do equilíbrio e da dinâmica dos recursos naturais. A estas alterações está associado um aumento na geração de cargas poluentes que atingem os sistemas hídricos.

As condições atuais de disponibilidade e demanda mostram que na média e na maior parte do território brasileiro não existe déficit de recursos hídricos. No entanto, observam-se situações desfavoráveis em períodos de estiagem no semi-árido brasileiro e em cidades de médio

\footnotetext{
${ }^{1}$ Parte da dissertação de mestrado desenvolvido pelo primeiro autor.

${ }^{2}$ Engenheiro Agrícola, Mestre em Engenharia Agrícola - Departamento de Engenharia/DEG - Universidade Federal de Lavras/UFLA - Cx. P. 3037 37200-000 - Lavras, MG - brasil ufla@yahoo.com.br.

${ }^{3}$ Engenheiro Agrônomo,Doutor em Hidráulica e Saneamento - Departamento de Engenharia/DEG -Universidade Federal de Lavras/UFLA - Cx. P. 3037 37200-000 - Lavras, MG - marciano@ufla.br.

${ }^{4}$ Engenheiro Agrícola,Doutor em Ciência do Solo - Departamento de Engenharia/DEG - Universidade Federal de Lavras/UFLA - Cx. P. 3037 - 37200 000 - Lavras, MG - crmello@ufla.br.

${ }^{5}$ Engenheiro Agrícola,Doutor em Engenharia Agrícola - Departamento de Engenharia/DEG - Universidade Federal de Lavras/UFLA - Cx. P. 3037 37200-000 - Lavras, MG - coelho@ufla.br.
} 
e grande porte (TUCCI et al., 2000). O mesmo autor ressalta, ainda, que as grandes concentrações brasileiras apresentam condições críticas de sustentabilidade, em razão do excesso de cargas de poluição doméstica e industrial e à ocorrência de enchentes urbanas, que contaminam os mananciais.

Segundo Sperling (1996), poluição das águas, é a adição de substâncias ou de formas de energia que, diretamente ou indiretamente, alteram a natureza do corpo d'água de uma maneira que prejudiquem os legítimos usos que dele são feitos.

As variedades de poluentes lançados nos corpos d'água podem ser agrupadas em duas grandes classes: pontual e difusa. Fontes pontuais de poluição são caracterizadas por uma descarga concentrada, em um ponto bem definido, como na saída de uma tubulação. As principais contribuições desta natureza se devem a sistemas de esgoto sanitário urbano não tratado ou parcialmente tratado e descargas industriais (NOVOTNY, 2003). A magnitude da poluição não pontual, ou difusa, pelo mundo é enorme. Por causa desta fonte de poluição, milhões de pessoas sofrem com doenças de veiculação hídrica, bilhões de dólares em investimentos de desenvolvimento econômico são perdidos e trilhões de dólares em passivo ambiental estão sendo acumulados para as próximas gerações assumirem (DUDA, 1993). Quanto à origem da poluição difusa, os ambientes considerados mais importantes são o rural (atividades de agricultura e pecuária) e o urbano (atividades residenciais, comerciais e industriais). Para cada tipo de uso do solo na bacia hidrográfica, pode-se observar características quantitativas e qualitativas de escoamento superficial bastante distintas (TONG \& CHEN, 2002; WURBS \& JAMES, 2002).

O uso e ocupação do solo implicam distintos comportamentos nos atributos do solo e da água, sendo que a remoção das florestas tem causado aumento significativo dos processos que levam à degradação de imensas áreas, com prejuízos aos recursos hídricos e à biodiversidade. Rizzi (1981) aborda aspectos associados à importância das florestas nativas na produção e conservação dos mananciais hídricos, com funções de interceptar a água da chuva, proporcionar condições ótimas de infiltração e reduzir o escoamento superficial. O deflúvio superficial, em bacias hidrográficas com topografia acentuada, exploradas por agricultura e pecuária, apresentam grande energia para desagregar o solo exposto e de transportar sedimentos para os corpos d'águas. Estes sedimentos são capazes de carregar, adsorvidos na sua superfície, nutrientes como o fósforo, compostos tóxicos como agroquímicos, além de material fecal presente em pastagens (MERTEN \& MINELLA, 2002).
Na caracterização da qualidade da água, utilizamse alguns parâmetros que representam suas características físico-químicas e biológicas, os indicadores de qualidade da água, que representam impurezas quando ultrapassam a certos valores estabelecidos. Estes parâmetros foram estabelecidos pela National Sanitation Foundation (NSF) dos Estados Unidos da América, por meio de pesquisas junto a vários especialistas da área ambiental, para o desenvolvimento de um índice que indicasse a qualidade da água, o Índice de Qualidade da Água (IQA). Baseado neste estudo, o Instituto Mineiro de Gestão das Águas (IGAM) modificou o IQA (IGAM, 2003) adequando-o para as condições brasileiras. Carvalho et al. (2000), utilizaram o IQA-IGAM para avaliar a qualidade da água do Ribeirão Ubá. Constataram que, a partir da entrada da cidade, bem como à jusante desta, a água do Ribeirão Ubá é de má qualidade, sofrendo tanto por poluição pontual (esgotos domésticos e efluentes industriais) quanto por poluição difusa (agricultura e pecuária).

Neste contexto, objetivou-se com este trabalho, avaliar a qualidade da água na bacia hidrográfica do ribeirão Lavrinha, ao longo do tempo, por meio do índice de qualidade de água proposto pelo IGAM (IGAM, 2003), e associar os resultados, ao uso dos recursos naturais e verificar o provável enquadramento do ribeirão em classes estabelecidas pela Resolução CONAMA 357/05.

\section{MATERIAL E MÉTODOS}

A área de estudo possui 687 ha, e compreende a bacia hidrográfica do Ribeirão Lavrinha (Figura 1), o qual desagua diretamente no Rio Grande, principal formador do Reservatório da UHE de Camargos/CEMIG, MG. Situa-se no município de Bocaina de Minas e entre as altitudes de $1159 \mathrm{~m}$ e $1737 \mathrm{~m}$. Esta área foi escolhida previamente como sendo representativa da região da Serra da Mantiqueira, sendo caracterizada como uma bacia hidrográfica de cabeceira.

O clima da região, segundo classificação Köppen, é do tipo CWb (JUNQUEIRA JUNIOR et al., 2007), caracterizado como mesotérmico de verões brandos e suaves, com estiagem de inverno. A temperatura média anual está em torno de $18^{\circ}$, tendo no mês mais quente e no mês mais frio uma temperatura média de $25,6^{\circ}$ e $13,1^{\circ}$, respectivamente, com ocorrências de geadas anualmente.

Na Figura 1, encontra-se a localização da área no estado de Minas Gerais e a bacia hidrográfica do Ribeirão Lavrinha com os pontos de amostragem de qualidade da água, usuários de água, hidrografia e modelo digital de elevação. 

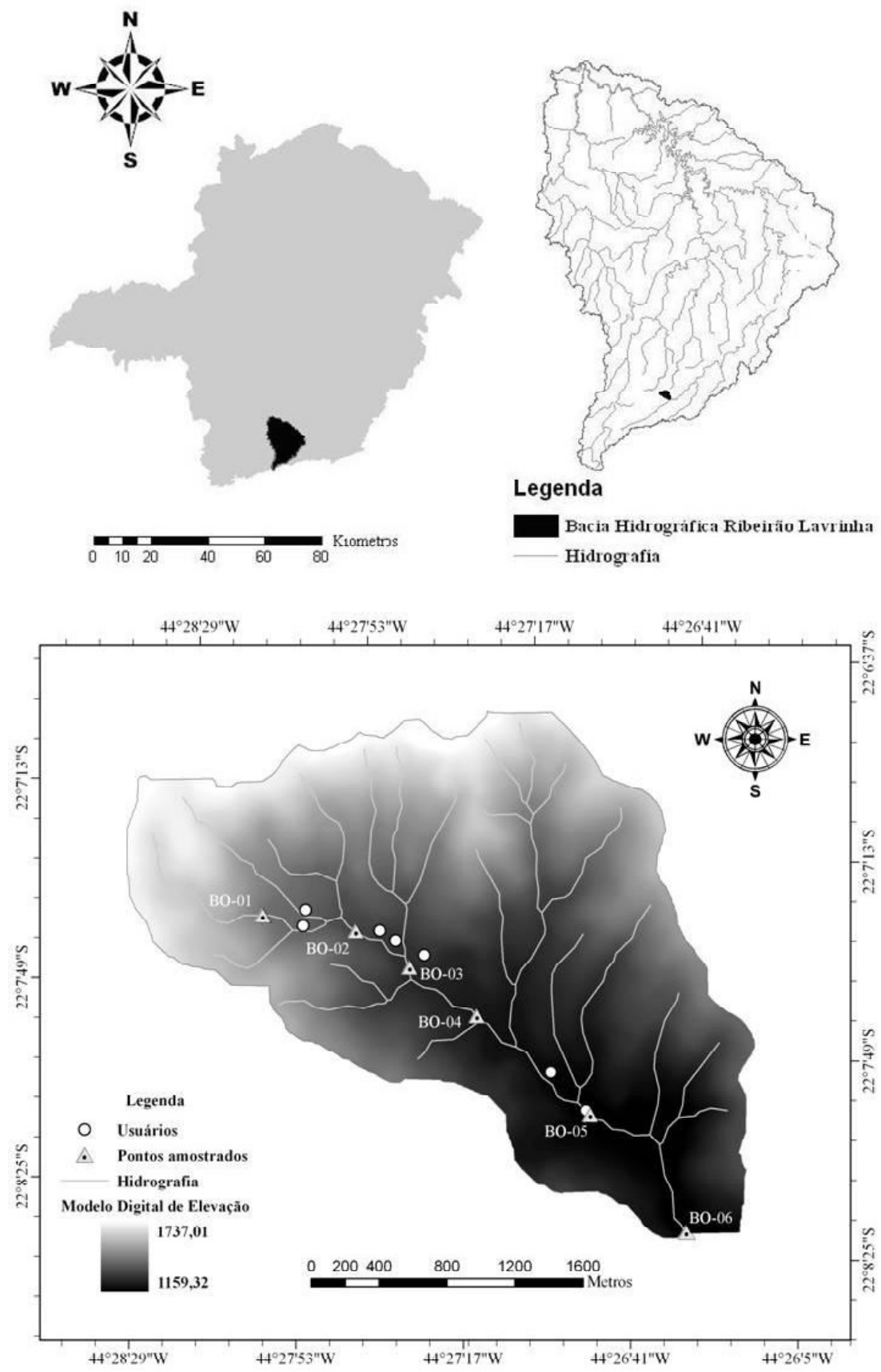

Figura 1 - UPGRH GD1 no Estado de Minas Gerais, localização da área dentro do GD1 e a bacia hidrográfica do Ribeirão Lavrinha com pontos de amostragem, usuários de água, hidrografia e modelo digital de elevação.

Os locais de amostragem da qualidade da água foram escolhidos mediante fatores que potencialmente poderiam influenciar, diretamente ou indiretamente, de forma significativa, a qualidade do corpo d'água, incluindo descargas, tanto pontuais quanto difusas, e captações, as quais podem ter efeito significativo nos resultados.

O tipo de amostra adotado neste estudo foi o da amostragem simples, onde em um ponto central da seção transversal do rio, a uma profundidade de 15 a $30 \mathrm{~cm}$ da 
superfície, retira-se a amostra, tanto para a análise "in situ" quanto para a análise laboratorial. Adotou-se uma metodologia específica de coleta e preservação de amostras, baseada no roteiro do APHA (1995), para garantir o acondicionamento e o armazenamento adequados, além do tempo máximo permitido entre a coleta e a análise, de maneira a não comprometer a integridade da amostra e, conseqüentemente, os resultados das análises. As amostragens foram sazonais de forma a descrever o comportamento dos corpos d'água ao longo das estações climáticas, totalizando sete amostras no período de abril de 2006 a janeiro de 2007.

Os parâmetros pH, oxigênio dissolvido, temperatura, condutividade elétrica e salinidade foram analisados no campo com o auxilio de um equipamento multi-parâmetro. Os parâmetros demanda bioquímica de oxigênio (DBO), demanda química de oxigênio (DQO), sólidos totais, sólidos totais dissolvidos, coliformes totais e coliformes termotolerantes foram analisados no Laboratório de Análise de Água do Departamento de Engenharia (LAADEG) e os parâmetros fósforo, nitrogênio amoniacal, nitrato e turbidez no Laboratório de Análise do Departamento de Ciência do Solo (DCS), seguindo as normas do APHA (1995).

Aos dados de qualidade da água foi aplicado o Índice de Qualidade de Água (IQA) proposto pelo IGAM (IGAM, 2003), sendo calculado com base nos parâmetros: OD, coliformes termotolerantes, $\mathrm{pH}, \mathrm{DBO}$, $\mathrm{NO}_{3}^{-}, \mathrm{PO}_{4}$, temperatura, turbidez e sólidos totais. A cada parâmetro foi adotado um peso pelo IGAM, conforme sua importância no cálculo do IQA apresentados na Tabela 1.

Tabela 1 - Pesos dos parâmetros de qualidade aplicados no cálculo do IQA.

\begin{tabular}{|c|c|c|}
\hline Parâmetro & Unidades & Peso - Wi \\
\hline Oxigênio Dissolvido - (OD) & $\% \mathrm{OD}$ & 0,17 \\
\hline $\begin{array}{l}\text { Coliformes } \\
\text { termotolerantes - (CF) }\end{array}$ & $\begin{array}{l}\text { NMP } \\
100 \mathrm{~mL}^{-1}\end{array}$ & 0,15 \\
\hline $\begin{array}{l}\text { Potencial } \\
\text { Hidrogeniônico - }(\mathrm{pH})\end{array}$ & $\mathrm{pH}$ & 0,12 \\
\hline $\begin{array}{l}\text { Demanda Bioquímica de } \\
\text { Oxigênio - (DBO) }\end{array}$ & $m g L^{-1}$ & 0,10 \\
\hline Nitratos $-\left(\mathrm{NO}_{3}^{-}\right)$ & $\mathrm{mg} \mathrm{L}^{-1}$ & 0,10 \\
\hline Fosfatos - $\left(\mathrm{PO}_{4}\right)$ & $\mathrm{mg} \mathrm{L}^{-1}$ & 0,10 \\
\hline $\begin{array}{l}\text { Variação de } \\
\text { Temperatura - }(\mathrm{T})\end{array}$ & ${ }^{\circ} \mathrm{C}$ & 0,10 \\
\hline Turbidez - (Tu) & UNT & 0,08 \\
\hline Resíduos Totais - (ST) & $\mathrm{mg} \mathrm{L}^{-1}$ & 0,08 \\
\hline
\end{tabular}

Fonte: IGAM (2003).
O IQA é calculado pelo produtório ponderado das qualidades de água correspondentes aos parâmetros conforme a fórmula:

$$
I Q A=\prod_{i=1}^{9} q_{i}^{{ }^{w_{i}}}
$$

Em que: IQA é o índice de qualidade da água, $\mathrm{q}_{\mathrm{i}}$ é a qualidade do parâmetro i obtido por meio da curva média especifica de qualidade e $\mathrm{w}_{\mathrm{i}}$ é o peso atribuído ao parâmetro, em função da sua importância na qualidade, entre 0 e 1 . Os valores do IQA variam de zero a cem, conforme especificado na Tabela 2.

Tabela 2 - Classificação do nível de qualidade conforme valores de IQA.

\begin{tabular}{cc}
\hline Nível de Qualidade & Faixa \\
\hline Excelente & $90<$ IQA $<100$ \\
Bom & $70<$ IQA $<90$ \\
Médio & $50<$ IQA $<70$ \\
Ruim & $25<$ IQA $<50$ \\
Muito Ruim & $0<$ IQA $<25$ \\
\hline
\end{tabular}

Fonte: IGAM (2003).

\section{RESULTADOS E DISCUSSÃO}

Na Tabela 3, encontra-se o uso atual do solo da bacia hidrográfica do Ribeirão Lavrinha. Verifica-se a predominância de ocupação por mata nativa e pastagem devido à pecuária leiteira, seguida da regeneração e por último a ocupação por várzea.

Tabela 3 - Uso atual do solo na bacia hidrográfica do Ribeirão Lavrinha.

\begin{tabular}{ccc}
\hline Uso atual & Área (ha.) & Percentual (\%) \\
\hline Mata Nativa & 284,8 & 41,5 \\
Regeneração & 90,9 & 13,2 \\
Pastagem & 277,8 & 40,4 \\
Vegetação de & 33,5 & 4,9 \\
Várzea & & 100 \\
\hline Total & 687 & \\
\hline
\end{tabular}

Na Figura 2, encontra-se o mapa de uso atual do solo na bacia hidrográfica. As pastagens predominantes na área geralmente são naturais e de baixa capacidade suporte, ocorrendo também a presença de pastagens plantadas, estas, porém, em menor escala, uma vez que a 
região apresenta grande dificuldade de mecanização agrícola causada pelas declividades acentuadas e solos pouco profundos (Cambissolos). Por ser uma região bastante montanhosa e com grande variação de exposição à radiação solar, a preferência para formação de pastagens é a face sul da bacia, onde a incidência de luz solar é maior. Na face norte, a ocupação é predominantemente por mata, cuja formação florestal, classificada por Veloso et al. (1991), é composta de Floresta Ombrófila Densa Montana. Esta área possui camadas de vegetação claramente definidas, com copas das árvores formando uma cobertura, atingindo em determinados locais cerca de $20 \mathrm{~m}$ de altura. No interior da mata, o solo encontra-se protegido por serrapilheira, que chega a atingir $0,5 \mathrm{~m}$ de espessura.

Pelo mapa da Figura 2, observa-se que o ponto BO-01 encontra-se na cabeceira da área, sendo mata nativa a paisagem ao entorno do mesmo. O ponto BO-02 encontrase logo abaixo do ponto de cabeceira, tendo na margem direita a ocupação por pastagem e na margem esquerda mata. A regeneração natural e a mata nativa compõem a paisagem ao entorno do ponto $\mathrm{BO}-03$. O ponto $\mathrm{BO}-04$ localiza-se numa área de predominância de mata na margem esquerda e pasto na margem direita. Os pontos BO-05 e BO-06 encontram-se sob ocupação por vegetação de várzea e pastagens.

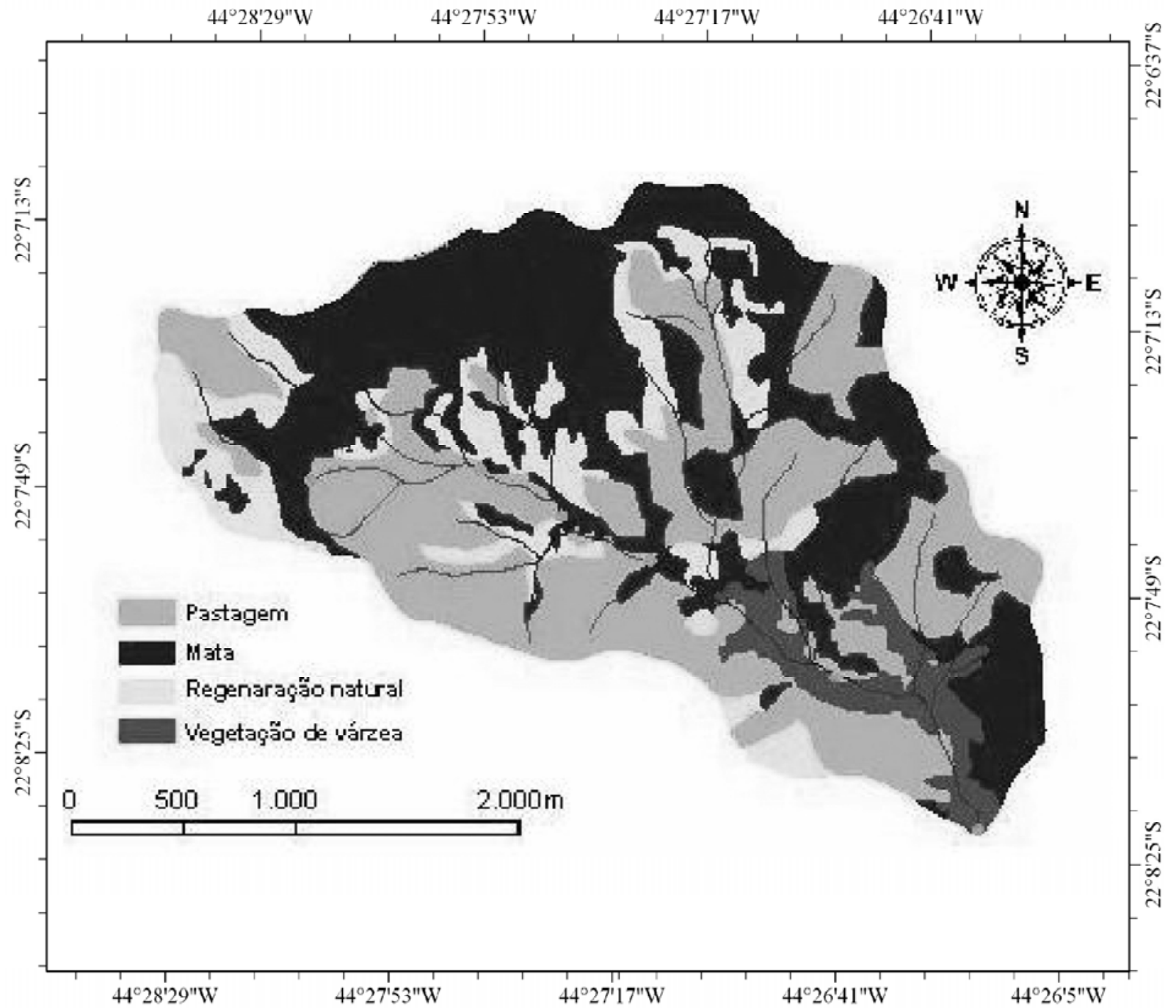

Figura 2 - Mapa de uso atual do solo na bacia hidrográfica do Ribeirão Lavrinha. 
$\mathrm{Na}$ bacia hidrográfica, encontra-se a Reserva Particular do Patrimônio Nacional Ave Lavrinha. A RPPN apresenta uma área de 49,01 ha e situa-se entre os pontos de amostragem de qualidade $\mathrm{BO}-02$ e $\mathrm{BO}$ - 04 na face norte da bacia.

Na Tabela 4, encontra-se o Índice de Qualidade da Água (IQA) calculado para cada ponto amostrado na bacia hidrográfica do Ribeirão Lavrinha.

Pelos dados da Tabela 4, nota-se que o comportamento do IQA, no mês de julho, foi excelente, tendo uma variação de 91,72 (ponto BO-06) a 95,52 (ponto BO-01). Estes altos índices estão ligados à ausência de coliformes termotolerantes neste período, pois, este parâmetro representa 17 \% no calculo do IQA. Uma possível causa da ausência de coliformes fecais é a rotatividade do gado nas pastagens e o baixo índice pluviométrico, nesta época do ano, na região (PINTO, 2007), não ocasionando, portanto, o escoamento superficial direto.

Os valores inferiores de IQA foram verificados na amostragem, do mês de maio, variando entre 50,89 (ponto BO-06) a 67,41 (ponto BO-01). No instante desta amostragem ocorria chuva e o escoamento superficial era nítido (PINTO, 2007), fato este que influenciou nos resultados obtidos, elevando os valores de coliformes, sólidos totais e sólidos totais dissolvidos.

Nota-se que, a partir do mês de outubro, quando as precipitações ficam mais freqüentes na região (PINTO, 2007), a qualidade da água sofre uma degradação. O efeito de diluição pela água da chuva não ocorreu, o que pode estar relacionado com o fato de o escoamento superficial direto transportar material orgânico e inorgânico, presente nas pastagens para dentro do ribeirão. Portanto, o efeito transportador do deflúvio foi maior que o de diluição. Este fato também foi observado por Carvalho \& Ferreira (2004) e Carvalho et al. (2000).
Do mês de setembro a janeiro, o IQA variou de 56,97 a 72,42, enquadrando-se em nível médio a bom de qualidade, conforme descrito na Tabela 2. As elevadas concentrações de coliformes termotolerantes coincidem com períodos de chuva na região (PINTO, 2007), sendo o escoamento superficial direto, o responsável pelo transporte do material fecal para as águas do ribeirão. Merten \& Minella (2002) relatam que as atividades de pecuária representam grande risco à qualidade de corpos d'água, quando nestas não são adotadas práticas de manejo conservacionistas, elevando os valores de DBO e coliformes fecais.

No geral, o IQA apresentou-se de nível bom, da cabeceira até o ponto BO-03 e nível médio do ponto BO04 até a seção controle, sendo o parâmetro coliformes termotolerantes o que mais interferiu no cálculo do índice de qualidade da água.

$\mathrm{O}$ fato de o IQA ser superior no trecho da cabeceira até o ponto $\mathrm{BO}-03$ e inferior deste até a seção controle, está intimamente relacionado com a ocupação do solo. No primeiro trecho, há predominância de ocupação por mata e regeneração natural, e a mata ciliar está presente nas margens do ribeirão Lavrinha. Já no segundo trecho, observa-se um domínio das pastagens na ocupação do solo, mesmo em locais considerados áreas de preservação permanente (APP). Além da ocupação do solo, práticas de manejo também interferem na qualidade da água. As queimadas são frequientes e adotadas como práticas de limpeza das pastagens, deteriorando tanto o solo quanto as águas da sub-bacia.

$\mathrm{Na}$ Tabela 5, apresenta-se um resumo do enquadramento em classes conforme Resolução CONAMA 357/05 para cada ponto amostrado.

Tabela 4 - Índice de Qualidade da Água nos pontos de amostragem na bacia hidrográfica do ribeirão Lavrinha, durante o período de monitoramento.

\begin{tabular}{ccccccc}
\hline Data de & \multicolumn{7}{c}{ IQA-(IGAM) } \\
\cline { 2 - 6 } amostragem & BO - 01 & BO - 02 & BO - 03 & BO - 04 & BO - 05 & BO - 06 \\
\hline $10 / 05 / 06$ & 67,41 & 64,71 & 64,44 & 63,56 & 57,41 & 50,89 \\
$03 / 07 / 06$ & 95,52 & 95,08 & 93,87 & 92,25 & 95,02 & 91,72 \\
$07 / 08 / 06$ & 94,78 & 71,25 & 70,79 & 70,60 & 73,19 & 69,15 \\
$17 / 09 / 06$ & 72,47 & 62,41 & 68,99 & 66,78 & 66,58 & 62,38 \\
$22 / 10 / 06$ & 71,61 & 71,24 & 68,57 & 61,77 & 59,96 & 56,97 \\
$03 / 12 / 06$ & 69,54 & 69,85 & 68,20 & 60,74 & 59,74 & 55,10 \\
$07 / 01 / 07$ & 76,53 & 75,13 & 70,86 & 69,51 & 68,95 & 68,04 \\
\hline
\end{tabular}


Tabela 5 - Resumo do enquadramento, de cada ponto amostrado na sub-bacia hidrográfica do ribeirão Lavrinha, em classes da Resolução CONAMA 357/05.

\begin{tabular}{cccc}
\hline Ponto & Enquadramento & Parâmetro Violado & Uso do solo no entorno do ponto \\
\hline BO-01 & Classe 3 & C. $\mathrm{T}$ & Mata nativa \\
\hline BO-02 & Classe 3 & C. T & Mata nativa, mata em regeneração e pastagem \\
\hline BO-03 & Classe 3 & C. T & Mata nativa, mata em regeneração e pastagem \\
\hline BO-04 & Classe 3 & C. T & Mata ciliar estreita e pastagem \\
\hline BO-05 & Classe 3 & C. T e OD & Pastagem \\
\hline BO-06 & Sem enquadramento & C.T, OD e DBO & Várzea e pastagem \\
\hline
\end{tabular}

Fonte: Conama (2005).

Do ponto BO-01 ao ponto BO-04, a maioria dos parâmetros apresentaram-se dentro dos limites da classe 1 , exceto coliformes termotolerantes, que violaram a classe 2 em uma amostragem, fazendo com que do ponto de cabeceira ao ponto BO-04, se enquadrassem na classe 3 . Os valores de coliformes fecais variaram de 0 a $4.500 \mathrm{NMP} /$ $100 \mathrm{ml}$, sendo que a Resolução CONAMA 357/05 estabelece o limite de 200 coliformes em $80 \%$ ou mais de, pelo menos 6 amostras coletadas bimestralmente ao longo do ano, para a classe 1 e de 1.000 coliformes para a classe 2 .

O ponto BO-05 também foi enquadrado na classe 3 , em razão do mesmo problema anterior, ou seja, os coliformes termotolerantes foram determinantes no enquadramento. $\mathrm{O}$ oxigênio dissolvido apresentou valores abaixo de $6 \mathrm{mg} \mathrm{L}^{-1}\left(5,45 \mathrm{mg} \mathrm{L}^{-1}\right.$ amostragem do dia 03/12/ 2006), sendo o limite da classe 1 estabelecido pela Resolução não inferior, em nenhuma amostra, a $6 \mathrm{mg} \mathrm{L}^{-1}$, fazendo com que este parâmetro levasse o enquadramento em classe 2. Porém, foram encontrados valores de até $2,5 \times 10^{4} \mathrm{NMP} / 100 \mathrm{~mL}$ para o parâmetro coliformes termotolerantes, fazendo com que o ponto se enquadre na classe 3.

Na seção controle da sub-bacia (ponto BO - 06), foram encontrados valores de DBO acima de $3 \mathrm{mg} \mathrm{L}^{-1}$ (3,3 $\mathrm{mg} \mathrm{L}^{-1}$ amostragem do dia 10/05/2006), OD abaixo de $6 \mathrm{mg}$ . $\mathrm{L}^{-1}$ (5,35 $\mathrm{mg} \mathrm{L}^{-1}$ e 5,24mg L-1 nas amostragens dos dias 03/ $12 / 2006$ e 07/01/2007 respectivamente) o que enquadraria o curso d'água neste ponto na classe 2. Porém, encontraram-se valores de coliformes termotolerantes de $4,5 \times 10^{4} \mathrm{NMP} / 100 \mathrm{ml}$ (amostragem do dia 10/05/2006) e de $3,5 \times 10^{4} \mathrm{NMP} / 100 \mathrm{ml}$ (amostragem do dia 03/12/2006) valores estes superiores ao limite da classe 3 , impedindo o enquadramento do curso d'água neste ponto, mesmo na classe 3, pois a Resolução CONAMA 357/05 estabelece o limite de $4 \times 10^{3} \mathrm{NMP} / 100 \mathrm{ml}$ em $80 \%$ ou mais de, pelo menos 6 amostras coletadas bimestralmente ao longo do ano, para a classe 3. Sendo assim, o ponto BO - 06 enquadra-se na classe 4 da Resolução.
Como se pode observar o parâmetro coliformes termotolerantes foi determinante no enquadramento, reduzindo em alguns pontos, de classe 1 para a classe 3 , em outros de classe 2 para classe 3 e em um caso impossibilitando o enquadramento em qualquer classe.

Conforme analisado para o IQA, as condições ambientais também se refletem no processo de enquadramento, sendo novamente o uso e a ocupação do solo, os possíveis fatores determinantes desta situação. Constata-se ainda que o principal fator causador do quadro crítico é o NMP de coliformes, o qual se associa com a pecuária. Em menor escala o OD e a DBO são também fatores limitantes.

\section{CONCLUSÕES}

Diante dos resultados apresentados neste estudo, ressaltam-se as seguintes conclusões:

O Índice de Qualidade da Água apresenta-se como uma boa ferramenta de suporte á gestão dos recursos hídricos, mostrando boa sintonia com o processo de enquadramento nas classes de uso da água.

A pecuária extensiva, juntamente com o baixo nível tecnológico empregado nesta atividade, na bacia hidrográfica do ribeirão Lavrinha, foram determinantes no nível da qualidade da água, concorrendo para a elevação dos valores de coliformes termotolerantes e DBO.

A presença da mata nativa, de mata em processo de regeneração e nas áreas ciliares, explicam o melhor nível da qualidade da água em alguns trechos da bacia.

Práticas de manejo sustentável fazem-se necessárias na bacia hidrográfica para reduzir os problemas relacionados à poluição hídrica.

\section{REFERÊNCIAS BIBLIOGRÁFICAS}

AMERICAN PUBLIC HEALTH ASSOCIATION. Standard methods for the examination of water and wastwater. 19. ed. Washington, DC, 1995. 
CARVALHO, A. R.; SCHLITTLER, F. H. M.; TORNISIELO, V. L. Relações das atividades agropecuárias com parâmetros físicos e químicos da água, Química Nova, São Paulo, v. 23, n. 5, p. 618-622, set./out. 2000.

CARVALHO, C. F.; FERREIRA, A. L. Qualidade das águas do ribeirão Ubá - MG. Revista Escola de Minas, Ouro Preto, p. 1-8, jul./set. 2004.

\section{CONSELHO NACIONAL DO MEIOAMBIENTE.}

Resolução no 357, de 17 de março de 2005.

DUDA, A. M. Addressing nonpoint sources of water pollution must become an international priority. Water Science and Technology, Oxford, v. 28, n. 3/5, p. 1-11, 1993.

IGAM. 2003. Disponível em: <http://

www.igam.mg.gov.br/>. Acesso em: 1 abr. 2008.

JUNQUEIRA JÚNIOR, J. A.; GOMES, N. M.; MELLO, C. R. DE.; SILVA, A. M. DA. Precipitação provável para a Região de Madre de Deus, Alto Rio Grande: modelos de probabilidades e valores característicos. Ciência e Agrotecnologia, Lavras, v. 31, n. 3, p. 842-850, maio/jun., 2007.

MERTEN, G. H.; MINELLA, J. P. Qualidade da água em bacias hidrográficas rurais: um desafio atual para sobrevivência futura. Agroecologia e Desenvolvimento Rural Sustentável, Porto Alegre, v. 3, n. 4, out./dez. 2002.

NOVOTNY, V. Water quality: diffuse pollution and watershed management. New York: J. Wiley, 2003.
PINTO, D. B. F. Qualidade dos recursos hídricos superficiais em sub-bacias hidrográficas da região Alto Rio Grande - MG. 2007. 89 p. Dissertação (Mestrado em Engenharia de Água e Solo) - Universidade Federal de Lavras, Lavras, 2007.

RIZZI, N. E. Função da floresta na manutenção da qualidade da água para uso humano. Floresta, Curitiba, v. 15 , n. 1/2, p. 54-65, jan./dez. 1981.

SPERLING, M. von. Introdução à qualidade das águas e ao tratamento de esgotos: princípios do tratamento biológico de águas residuárias. Belo Horizonte: [s.n.], 1996. v. 1

TONG, S. T. Y.; CHEN, W. Modeling the relationship between land use and surface water quality. Journal of Environmental Management, New York, v. 66, p. 377-393, 2002.

TUCCI, C. E. M.; HESPANHOL, I.; CORDEIRO NETTO, O. M. Cenários da gestão da água no Brasil: uma contribuição para a visão mundial da água. Revista Brasileira de Recursos Hídricos, v. 5, n. 3, p. 31-43, 2000.

VELOSO, H. P.; RANGEL FILHO, A. L. R.; LIMA, J. C. A. Classificação da vegetação brasileira, adaptado a um sistema universal. Rio de Janeiro: IBGE, 1991. $123 \mathrm{p}$.

WURBS, R. A.; JAMES, W. P. Water resources engineering. London: Prentice Hall, 2002. 